\title{
Quantitative Trait Loci (QTL) Analysis Reveals Both Broad-Spectrum and Isolate-Specific QTL for Scab Resistance in an Apple Progeny Challenged with Eight Isolates of Venturia inaequalis
}

\author{
F. Calenge, A. Faure, M. Goerre, C. Gebhardt, W. E. Van de Weg, L. Parisi, and C.-E. Durel
}

\begin{abstract}
First, second, and seventh authors: Institut National de la Recherche Agronomique (INRA), Unité Mixte de Recherche Génétique et Horticulture GenHort, 42 rue Georges Morel, BP 57, 49071 Beaucouzé cedex, France; third author: FAW-Swiss Federal Research Station for Fruit-Growing, Viticulture and Horticulture, 8820 Wädenswil, Switzerland; fourth author: Max-Planck-Institute for Breeding Research, Carl von Linne Weg, 10, 50829 Cologne, Germany; fifth author: Plant Research International, P.O. Box 16, Droevendaalsesteeg 1, 6700 AA Wageningen, The Netherlands; and sixth author: INRA, Unité Mixte de Recherche en Pathologie Végétale, 42 rue Georges Morel, BP 57, 49071 Beaucouzé cedex, France.
\end{abstract}

Accepted for publication 29 November 2003

\begin{abstract}
Calenge, F., Faure, A., Goerre, M., Gebhardt, C., Van de Weg, W. E., Parisi, L., and Durel, C.-E. 2004. Quantitative trait loci (QTL) analysis reveals both broad-spectrum and isolate-specific QTL for scab resistance in an apple progeny challenged with eight isolates of Venturia inaequalis. Phytopathology 94:370-379.

The major scab resistance gene $V f$, extensively used in apple breeding programs, was recently overcome by the new races 6 and 7 of the fungal pathogen Venturia inaequalis. New, more durable, scab resistance genes are needed in apple breeding programs. $\mathrm{F}_{1}$ progeny derived from the cross between partially resistant apple cv. Discovery and apple hybrid 'TN10-8'

were inoculated in the greenhouse with eight isolates of $V$. inaequalis, including isolates able to overcome $V f$. One major resistance gene, $V g$, and seven quantitative trait loci (QTL) were identified for resistance to these isolates. Three QTL on linkage group (LG)12, LG13, and LG15 were clearly isolate-specific. Another QTL on LG5 was detected with two isolates. Three QTL on LG1, LG2, and LG17 were identified with most isolates tested, but not with every isolate. The QTL on LG2 displayed alleles conferring different specificities. This QTL co-localized with the major scab resistance genes $V r$ and $V h 8$, whereas the QTL on LG1 colocalized with $V f$. These results contribute to a better understanding of the genetic basis of the $V$. inaequalis-Malus $\times$ domestica interaction.
\end{abstract}

Apple scab, caused by the fungal agent Venturia inaequalis (Cooke) G. Wint., is one of the most important diseases of apple (Malus $\times$ domestica Borkh.) worldwide. Most commercial apple cultivars are susceptible to this disease. Scab occurs in every country where apple is cultivated, but it is a serious problem mainly in temperate regions with cool, moist weather in early spring. Its control requires 12 to 15 fungicide sprays per year in a commercial orchard, thus leading to high production costs and environmental and health concerns for consumers (37).

The use of genetically scab-resistant cultivars is an alternative to the chemical control of the disease. Several resistance genes have been identified in the apple germ plasm. By 1969, five scab resistance genes had been identified in wild apple species (56): $V f$ in $M$. floribunda clone 821, $V r$ in $M$. pumila, $V m$ in M. micromalus, $V b$ in $M$. baccata, and $V b j$ in $M$. baccata jackii. A sixth gene for resistance, $V a$, was identified in apple cv. Antonovka P.I. 172623 (32). Seven additional resistance genes were more recently identified: $V f h$ in M. floribunda 821 (5); $V g$ in 'Golden Delicious' and 'Prima' $(4,18) ; V x$ in M. pumila R12740-7A (25); $V h 2$ and $V h 4$ in two accessions derived from M. pumila R127407A (7), which could be $V r$ and $V x$, respectively (46); $V r 2$ in R12740-7A (46); and $V h 8$ in an M. sieversii accession (8). $V g, V f$, and $V h 8$ were shown to be involved in gene-for-gene relationships (19) with $V$. inaequalis $(5,8)$. $V f$ from $M$. floribunda was the first gene to be introgressed successfully in $M . \times$ domestica. The first cultivar carrying Vf, named 'Prima', was released in 1970

Corresponding author: C.-E. Durel; E-mail address: durel@angers.inra.fr

Publication no. P-2004-0212-01R

(c) 2004 The American Phytopathological Society
(14). In 1999, more than $80 \%$ of the scab-resistant cultivars included in breeding programs carried the $V f$ gene (29). This gene confers a strong resistance to races 1 to 5 of $V$. inaequalis (32).

Two new races of $V$. inaequalis (races 6 and 7) able to overcome $V f$ were recently isolated and characterized $(43,48)$. Race 7 was shown to be avirulent on cvs. Golden Delicious and Prima, carrying $V g$ (5). Race 6 is avirulent on $M$. floribunda 821, due to the presence of a major gene, Vfh (6). New resistance genes against these new races are needed in apple breeding programs to create new cultivars with a durable resistance to scab, or at least a resistance efficient against all known races of $V$. inaequalis, including the new races 6 and 7. Polygenic, partial resistance has rarely been taken into account in apple breeding programs worldwide. This type of resistance is often hypothesized to be more durable than monogenic resistance. It could provide new, more durable scab resistance genes. In fact, erosion of quantitative polygenic resistance has not yet been clearly proven in any pathosystem (44). In apple, partial resistance has been observed for a long time in addition to complete resistance conferred by major resistance genes. This type of resistance is characterized by a reduced sporulation on leaves or fruits (37). Sporulation is observed only under very wet conditions, not every year, and is not followed by a progressive invasion of the leaf or fruit tissues as observed for susceptible cultivars.

Several genetic linkage maps have been constructed in apple $(13,26,35,38)$ as a prerequisite to map both major resistance genes and quantitative trait loci (QTL). Partial scab resistance in three apple cultivars (Prima, Fiesta, and Discovery) was recently demonstrated to be polygenically inherited $(17,36)$. 'Prima' and 'Fiesta' were shown to possess QTL for resistance to two monoconidial isolates of race 6 (17). 'Discovery' and 'Fiesta' were 
shown to possess QTL for resistance to $V$. inaequalis in the field, in Switzerland (36). In these studies, only one or two isolates per inoculum of $V$. inaequalis were tested. Testing more isolates of $V$. inaequalis would lead to a better understanding of the nature of quantitative scab resistance in apple. In particular, knowing the spectrum of action of individual QTL toward the different races of $V$. inaequalis is crucial for the construction of new genotypes carrying a broad-spectrum resistance to scab.

In this study, we used a QTL analysis approach to study the genetic determinism underlying the partial resistance of an $F_{1}$ apple progeny derived from the cross between apple cv. Discovery and apple hybrid 'TN10-8', and challenged with eight different isolates of $V$. inaequalis, including four isolates able to overcome $V f$. Our objectives were to (i) determine the number, genomic position, and effects of the QTL for resistance to each tested isolate and (ii) determine the spectrum of action of each detected QTL toward the set of isolates tested. To our knowledge, this is the first in-depth study of the genetic determinism of partial scab resistance in apple in regard to $V$. inaequalis variability.

\section{MATERIALS AND METHODS}

Plant materials. A progeny of $149 \mathrm{~F}_{1}$ individuals was derived from a cross between the partially resistant cv. Discovery (female parent) and the partially resistant hybrid 'TN10-8' (male parent). This progeny was sown in 1997 in a French orchard. 'Discovery' is an English cultivar derived from 'Worcester Pearman' $\times$ 'Beauty of Bath'. 'TN10-8' is a French hybrid derived from a cross between the scab-tolerant French cv. Reinette Clochard and a scab-resistant hybrid derived from 'Schmidt's Antonovka P.I. 172632'. 'Schmidt's Antonovka P.I. 172632' is different from 'Schmidt's Antonovka P.I. 172623', which carries the major resistance gene $\mathrm{Va}$ (Y. Lespinasse, personal communication). There is no symptom similar to the pit-type symptom caused by $V a$ on its leaves. It is not known whether its resistance is qualitative or quantitative. Before this study, neither 'Discovery' nor 'TN10-8' was known to possess any major resistance gene. In particular, their pedigrees do not include $M$. floribunda 821, i.e., the original source of $V f$.

Inocula. Six monoconidial isolates (genetically homogeneous), one mixture of isolates (genetically heterogeneous), and one isolate (genetically heterogeneous) of $V$. inaequalis were used (Table 1 ). The monoconidial isolates 104, 302, and 1066 are reference isolates for races 1, 6, and 7 from the collection of the Institut $\mathrm{Na}$ tional de la Recherche Agronomique (INRA), Angers, France (5). The monoconidial isolates EU-B04, EU-D42, and EU-NL24 belong to the European collection of $V$. inaequalis, from the European project Durable Apple Resistance in Europe (33). Isolate EU-B04 was selected for its high aggressiveness. Isolate EU-D42 belongs to race 6 . Isolate EU-NL24 combines the virulences of races 6 and 7 (L. Parisi, unpublished data). Isolate $\mathrm{Gd}-\mathrm{CH}$ was collected from 'Golden Delicious' at the Swiss Federal Research Station for Fruit-Growing, Viticulture and Horticulture (FAW), Wädenswil, Switzerland. Isolate MLI is a mixture of isolates collected in several local orchards in Angers, France. Similar mixtures are prepared every year to select resistant apple genotypes in the breeding program carried out at INRA. Each inoculum was prepared as described by Parisi and Lespinasse (42) to obtain a final concentration of $3 \times 10^{5}$ conidia per $\mathrm{ml}$.

Pathological tests and disease assessments. All resistance tests were carried out in the greenhouse with the 149 individuals of the progeny, parents 'Discovery' and 'TN10-8', and susceptible control cultivars. Seven tests were performed at INRA. The first test was performed with isolate 302 on the young, nongrafted $\mathrm{F}_{1}$ trees (seedlings). For the following tests, tree scions of each genotype could be grafted on the apple rootstock 'MM106' so that replicates of genotypes could be used. A randomized complete block design was used, with one genotype replicate per block. One to six replicates (blocks) per test were used (Table 2).

TABLE 1. Characteristics of the Venturia inaequalis inocula used for the pathological tests performed on the 'Discovery' $\times$ 'TN10-8' progeny

\begin{tabular}{|c|c|c|c|c|c|c|c|}
\hline \multirow[b]{2}{*}{ Inoculum } & \multirow[b]{2}{*}{ Origin $^{a}$} & \multirow[b]{2}{*}{ Country } & \multirow[b]{2}{*}{ Type $^{b}$} & \multirow[b]{2}{*}{ Race } & \multicolumn{3}{|c|}{ Virulence $^{c}$} \\
\hline & & & & & $V f$ & $V g$ & $M f$ \\
\hline EU-B04 & 'Golden Delicious' & Belgium & MI & 1 & - & + & - \\
\hline 104 & 'Golden Delicious' & France & MI & 1 & - & + & - \\
\hline 302 & 'Prima' $\times$ 'A143/24'd & Germany & MI & 6 & + & + & - \\
\hline EU-D42 & 'Prima' & Germany & MI & 6 & + & + & - \\
\hline EU-NL24 & 'Prima' & The Netherlands & MI & $\ldots^{\mathrm{e}}$ & + & + & + \\
\hline 1066 & Malus floribunda 821 & France $^{f}$ & MI & 7 & + & - & + \\
\hline MLI & Local orchards & France & MIX & $\ldots$ & $\ldots$ & $\ldots$ & $\ldots$ \\
\hline $\mathrm{Gd}-\mathrm{CH}$ & 'Golden Delicious' & Switzerland & I & $\ldots$ & $\ldots$ & $\ldots$ & $\ldots$ \\
\hline
\end{tabular}

a Cultivars from which isolates were collected.

b Genetic composition of the inocula: MI, monoconidial isolate; MIX, mixture of isolates; and I, isolate.

c Virulences of inocula to scab resistance genes $V f$ and $V g$ and to clone 821 of the wild apple species $M$. floribunda (Mf): +, virulent; and -, avirulent.

d Strain 302 was collected on a tree derived from this cross (42).

e Inoculum not characterized.

f Strain originating from the English isolate described by Roberts and Crute (48).

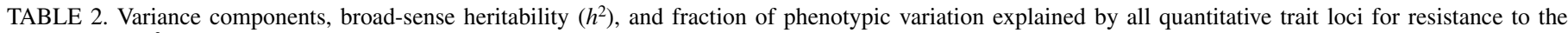
same isolate $\left(R^{2}\right)$ associated with the mean infection type in the 'Discovery' $\times$ 'TN10-8' progeny for each pathological test ${ }^{\mathrm{a}}$

\begin{tabular}{|c|c|c|c|c|c|c|c|}
\hline \multirow[b]{2}{*}{ Date } & \multirow[b]{2}{*}{ Inoculum } & \multirow{2}{*}{$\begin{array}{c}\text { Number of } \\
\text { genotype replicates }\end{array}$} & \multicolumn{3}{|c|}{ Variance components } & \multirow[b]{2}{*}{$R^{2}$} & \multirow[b]{2}{*}{$h^{2}$} \\
\hline & & & Mean & $\sigma_{g}^{2}$ & $\sigma_{e}^{2}$ & & \\
\hline 1997 & 302 & 1 & $3.41 \pm 1.23$ & $\ldots$ & $\ldots$ & 0.38 & $\ldots$ \\
\hline 1999 & 1066 & 3 & $3.12 \pm 1.16$ & $1.04 \pm 0.56$ & $0.39 \pm 0.04$ & 0.84 & 0.87 \\
\hline 2000 & $\begin{array}{l}\text { EU-D42 } \\
104 \\
\text { Gd-CH }\end{array}$ & $\begin{array}{l}3 \\
3 \\
1\end{array}$ & $\begin{array}{l}4.40 \pm 0.61 \\
1.26 \pm 1.45 \\
2.06 \pm 1.31\end{array}$ & $\begin{array}{c}\ldots \\
0.58 \pm 0.53 \\
\ldots\end{array}$ & $\begin{array}{c}\ldots \\
1.55 \pm 0.14 \\
\ldots\end{array}$ & $\begin{array}{l}0.13 \\
0.31 \\
0.27\end{array}$ & $\begin{array}{c}\ldots \\
0.51 \\
\ldots\end{array}$ \\
\hline 2001 & $\begin{array}{l}\text { EU-NL24 } \\
\text { EU-B04 }\end{array}$ & $\begin{array}{l}6 \\
6\end{array}$ & $\begin{array}{l}4.19 \pm 1.17 \\
3.09 \pm 0.85\end{array}$ & $\begin{array}{l}0.32 \pm 0.25 \\
0.60 \pm 0.28\end{array}$ & $\begin{array}{l}0.59 \pm 0.03 \\
0.68 \pm 0.04\end{array}$ & $\begin{array}{l}0.38 \\
0.61\end{array}$ & $\begin{array}{l}0.76 \\
0.90\end{array}$ \\
\hline 2002 & MLI & 6 & $2.78 \pm 1.16$ & $1.21 \pm 0.28$ & $0.70 \pm 0.04$ & 0.48 & 0.63 \\
\hline
\end{tabular}

a Value \pm standard deviation. ... indicates not calculated because only one replicate was used. 
Another test was performed in the greenhouse at FAW, Switzerland, with isolate $\mathrm{Gd}-\mathrm{CH}$, without genotype replicates, with trees grafted on 'MM106'. After grafting, trees were grown in the greenhouse for at least 6 weeks until they produced 8 to 10 leaves per shoot on average. For each inoculation, the inoculum was sprayed on the trees so that every leaf was reached. Spraying was maintained until droplets appeared on the leaves and stopped before streaming. Hygrometry was maintained at $90 \%$ and temperature at $18^{\circ} \mathrm{C}$ during $48 \mathrm{~h}$ to allow conidia germination. Then, hygrometry was reduced to $70 \%$ and temperature to $17^{\circ} \mathrm{C}$. For each test, the germination rate of conidia from a sample of the inoculum used for the test was checked on agar plates.

Two traits were scored on leaves both 14 and 21 days after inoculation: infection type, i.e., an ordinal scale adapted from the scale defined by Chevalier et al. (11), and sporulation severity (sporulation), i.e., an ordinal scale corresponding to the percentage of leaf surface showing sporulation (described by Croxall et al. [15] and modified by Parisi et al. [43]). Infection type was defined as follows: $0=$ no symptom; $1=$ (pinpoint-sized) pits on the leaf surface; 2 = chlorotic or necrotic reactions, or a combination of both, with possible shrinkage of the leaf without sporulation; 3 = same symptoms as class 2 with reduced sporulation; $4=$ larger amount of sporulation with strong chlorotic or necrotic reactions, or a combination of both; and $5=$ sporulation without any resistance symptom visible. Individuals scored 0 to 3 were considered resistant, whereas individuals scored 4 or 5 were considered susceptible. Sporulation was assessed as follows: 0, no sporulation; $1,0<$ sporulation $\leq 1 \% ; 2,1 \%<$ sporulation $\leq 5 \%$; $3,5 \%<$ sporulation $\leq 10 \% ; 4,10 \%<$ sporulation $\leq 25 \% ; 5$, $25 \%<$ sporulation $\leq 50 \% ; 6,50 \%<$ sporulation $\leq 75 \%$; and 7 , $75 \%<$ sporulation $\leq 100 \%$. With isolate 1066 , a necrosis symptom appeared on leaves 7 days after inoculation, sometimes in addition to sporulation and other resistance symptoms, and was scored as a qualitative trait for its presence or absence on each genotype, 7 to 12 days after inoculation.

Genetic map construction. The 149 individuals of the 'Discovery' $x$ 'TN10-8' progeny were genotyped with isozyme (12), amplified fragment length polymorphism (AFLP) (53), and microsatellite markers $(23,34)$. Before mapping this progeny, 10 AFLP primer pairs were selected for their good overall coverage of the 'Discovery' genome as assessed in the previously mapped 'Fiesta' $\times$ 'Discovery' progeny (W. E. Van de Weg, unpublished data). Genetic mapping followed the double pseudo-testcross mapping strategy (24) developed for heterozygous outbreeding plants. All genetic maps were constructed with the Joinmap software version 2.0 (PRi, Wageningen, The Netherlands). A LOD (logarithm of odds ratio) threshold of 5 was used to define linkage groups (LGs). The Kosambi function was used to calculate genetic distances. Two genetic linkage maps were first constructed, one for each parent, using two sets of markers. Markers heterozygous for 'Discovery' and homozygous for 'TN10-8' were used for the map of 'Discovery', whereas markers heterozygous for 'TN10-8' and homozygous for 'Discovery' were used to construct the 'TN10-8' map. Codominant microsatellite markers were used to construct a single integrated linkage map with both sets of markers. When several markers clustered at the same position, the marker of best quality was conserved and other markers were discarded in order to construct a final framework linkage map.

Statistical analyses. For the five tests including replicates, statistical analyses of phenotypic data were conducted using the Statistical Analysis System (SAS) software (SAS Institute, Cary, NC). Each phenotypic value was subdivided into a block effect, a genotype effect, and residual effects. After analyses of variance (ANOVA), when a significant block effect was detected, individual values were adjusted according to their corresponding block by the following formula: $Y_{i j(\mathrm{adj})}=Y_{i j}+\left(\mu-\mu_{j}\right)$, where $Y_{i j}$ is the phenotypic value of individual $i$ in block $j, \mu$ is the overall mean of the progeny, and $\mu_{j}$ is the mean of individuals belonging to block $j$. For each test, Pearson correlation coefficients were calculated to assess phenotypic correlations between infection type and sporulation. Two variables were used to carry out QTL analyses: mean infection type and mean sporulation of each genotype over the blocks (i.e., over the replicates). Broad-sense heritabilities of these two variables were calculated as the ratio between the estimated genetic variance and the phenotypic variance with the following formula: $h^{2}=\sigma_{g}^{2} /\left(\sigma_{g}^{2}+\sigma_{e}^{2} / n\right)$, where $n$ is the mean number of replicates per genotype, $\sigma_{g}^{2}$ is the genetic variance, and $\sigma_{e}^{2}$ is the residual variance. Statistical differences between mean infection types and mean sporulations of 'Discovery' and 'TN10-8' obtained with different isolates were checked using a Bonferroni test (type I experimentwise error $=5 \%$ ).

QTL analyses. The software Map-QTL version 3.0. (PRi) was used with both the mean infection type and the mean sporulation to detect QTL. This software is able to deal with a full-sib family derived from heterozygous parents of a cross-pollinating species, as found in apple. QTL were searched on the entire progeny. For isolate 1066, QTL were searched both on the entire progeny and on the part of the progeny not displaying the necrosis symptom scored on leaves. QTL analyses were first performed with the separate genetic maps of 'Discovery' and 'TN10-8', thus leading to the detection of additive effects in a pseudo-testcross situation. Then the integrated framework linkage map was used, which allowed the detection of both additive and dominance effects. Whatever the map used, interval mapping was first performed. Then markers close to the likelihood peaks of the detected QTL were used as cofactors for restricted multiple QTL mapping (rMQM) analyses. A LOD threshold of 3 was used for declaring a putative QTL significant. For each significant QTL, a confidence interval corresponding to a LOD score drop off of 2 on either side of the likelihood peaks was calculated. Such an interval is supposed to contain the QTL with a probability over 95\% (51).

For each QTL, there are four different alleles: $a$ and $b$ for 'Discovery' and c and d for 'TN10-8'. Therefore, four different genotypic classes may derive from the cross between these parents: ac, $\mathrm{ad}, \mathrm{bc}$, and bd. On the separate maps, only markers heterozygous for one single parent are used, therefore only two different genotypic classes can be distinguished: a versus b for the 'Discovery' map and c versus d for the 'TN10-8' map. For each QTL, we determined the favorable allele by comparing the average phenotypic effects associated with the two genotypic classes distinguished when using the separate parental maps. When a QTL was detected only on the framework integrated linkage map, the most favorable genotypic class was determined.

For each pathological test, a multiway ANOVA was performed with molecular markers close to the QTL peaks to estimate the total percentage of phenotypic variation $\left(R^{2}\right)$ explained by the significant QTL.

\section{RESULTS}

Genetic mapping of the 'Discovery' $x$ 'TN10-8' progeny. The length of the final framework genetic map of the progeny was 1,219 centimorgans (cM). A total of 102 AFLP, 62 microsatellite, and 13 isozyme markers were used to construct this map. The average distance between two markers was $7.6 \mathrm{cM}$ (standard deviation $5.8 \mathrm{cM}$ ). The maximum distance was $32.1 \mathrm{cM}$. One hundred twenty-nine markers, mostly AFLP markers, showed a dominant segregation ratio (1:1), whereas 48 microsatellite or isozyme markers displayed three or four genotypic classes (1:2:1 or $1: 1: 1: 1)$ and were useful to merge the parental maps. Seventeen LGs were constructed, as expected for apple, with a genome of 17 chromosome pairs. Each LG included at least two codominant microsatellite markers, thus allowing LGs orientation in accordance with the reference maps $(35,38)$.

Disease assessment. Each inoculum tested had a germination rate above $70 \%$. Susceptible controls displayed sporulation on 
leaves for each test, with homogeneous infection types over replicates and some slight variations in sporulation.

Parents. Parents were always less susceptible than the control genotypes. Symptoms observed on parents often varied between replicates during the same experiment, but no parent was scored as both susceptible and resistant in the same experiment, except for 'Discovery' with isolate EU-NL24, with infection types ranging between 2 and 5 . The observation of the mean infection type and the mean sporulation over replicates shows that the resistance level of both parents varied greatly with the isolate tested (Table 3 ). Unfortunately, genotypes of the parents were not available during the test of isolate 302 , so their resistance level could not be checked during the experiment.

Progeny. In spite of the existence of variations in infection type and sporulation over replicates in the progeny, ANOVA led to the detection of significant differences among genotypes for each test. For each test, the number of susceptible individuals increased between 14 and 21 days after inoculation. Very few fully resistant individuals were observed, except with isolate 104, which means that very few escapes occurred during experiments. For isolate EU-D42, two of the three blocks inoculated were not scored, because in these blocks, numerous chlorosis symptoms appeared on leaves on every tree, which were probably not related with scab resistance symptoms. Therefore, for this isolate, only one replicate per genotype was finally taken into account. Block effects were significant for all tests with replicates, except with isolate 1066, therefore individual infection type and sporulation were adjusted according to the block effects. Comparison of mean infection type between experiments showed that the progeny was on average resistant (infection type of $\leq 3$ ) to isolates $104, \mathrm{Gd}-\mathrm{CH}$, and MLI and susceptible (infection type of $>3$ ) to isolates EUD42 and EU-NL24, whereas its resistance to isolates 302, 1066, and EU-B04 was intermediate (Table 2). The mean infection type and the mean sporulation were highly correlated, with Pearson correlation coefficients ranging from 0.66 to $0.93(P \leq 0.0001)$. Broad-sense heritability ranged from 0.51 to 0.90 depending on the isolate (Table 2). For isolates 302, EU-D42, and EU-NL24, the distribution of mean infection type in the progeny was skewed toward susceptibility, whereas it was skewed toward resistance for isolate 104 (Fig. 1).

Genetic mapping of a major resistance gene. Eighty of the 149 individuals of the progeny displayed the necrosis symptom scored on leaves 7 to 12 days after inoculation with isolate 1066 . Some individuals displayed both slight sporulation and necrosis symptoms on leaves, sometimes even on the same leaf. This symptom was mapped as a qualitative trait with the Joinmap software version 2.0 on LG12 at $0.5 \mathrm{cM}$ from the microsatellite marker CH01d03 (Fig. 2). The mapped gene was called $V g$ (described below). The mean infection type of the individuals displaying this necrosis symptom, 21 days after inoculation, was $2.3 \pm 0.6$ ( \pm standard deviation), whereas it was $4.1 \pm 0.7$ for the individuals not displaying it.

QTL analyses. A total of 24 QTL and one major gene distributed over six different genomic regions of the 'Discovery' $\times$ 'TN10-8' integrated framework linkage map were significantly associated with scab resistance. Eleven QTL were detected using the map of 'Discovery', whereas eight QTL were detected using the map of 'TN10-8'. These 19 QTL, and five additional QTL, were detected using the integrated linkage map. QTL were detected at similar map positions with mean infection type and mean sporulation, with almost equal LOD and $R^{2}$ values (percentage of phenotypic variation). Most QTL were detected 14 and 21 days after inoculation at similar map positions but with higher LOD scores 21 days after inoculation and more accurate positions. Only results obtained with the mean infection type by rMQM 21 days after inoculation are shown (Table 4). The $R^{2}$ each QTL accounted for ranged from 4.1 to $82.7 \%$ (Table 4 ). The total $R^{2}$ accounted for by all QTL for resistance to one isolate ranged from 13 to $84 \%$ (Table 2). Nineteen of the 24 QTL detected were located in only three different genomic regions on LG1, LG2, and LG17 (Fig. 2). These regions were detected with different LOD and $R^{2}$ values depending on the isolate tested (Table 4), but confidence intervals overlapped.

On LG1, QTL were detected with every isolate except isolates 302 (race 6) and 1066 (race 7). The QTL with the weakest effect was detected with isolate EU-NL24 $\left(R^{2}=4.1 \%\right)$. Although it was detected with a LOD smaller than 3 , it was not discarded because its map position was the same as that of the other QTL detected on this LG. The QTL with the strongest effect was detected with isolate MLI $\left(R^{2}=51.1 \%\right)$. All confidence intervals of these QTL overlapped on a common segment flanked by the markers PGM-1 and $\mathrm{CH}-V f_{1}$. For each QTL, the favorable allele was the c allele derived from 'TN10-8'.

On LG2, QTL were detected with every isolate except isolates Gd-CH ('Golden Delicious' isolate) and 1066 (race 7). QTL effects ranged from $5.1 \%$ (isolate MLI, mixture of isolates) to $25.8 \%$ (isolate 302 , race 6 ). The confidence intervals of all the QTL located on this LG overlapped. The resistance allele was a toward isolates EU-B04 and EU-NL24, c toward isolate 302, and $\mathrm{d}$ toward isolate MLI. The QTL for resistance to isolates 104 and EU-D42 on LG2 were detected only when using the integrated linkage map. The most favorable combination of alleles at these loci was a+d.

On LG5, two QTL with likelihood peaks close to the microsatellite marker $\mathrm{CHO} 4 \mathrm{e} 03$ were detected. One of them was involved in the resistance toward isolate EU-B04 (race 1). Its favorable effects were derived from the a allele of 'Discovery'. The other QTL was detected with isolate MLI (mixture of isolates). Favorable effects at this QTL were associated with the allele combination $\mathrm{a}+\mathrm{c}$.

On LG17, QTL were detected with every isolate except isolate 1066. QTL effects ranged from $4.7 \%$ (isolate MLI, mixture of isolates) to $19.4 \%$ (isolate 104 , race 1 ). The confidence intervals of all the QTL located on this region of LG17 overlapped. For QTL detected with isolates 104, EU-B04, 302, Gd-CH, and MLI, favorable effects were derived from the a allele of 'Discovery'. The QTL for resistance to isolates EU-D42 and EU-NL24 were detected only when using the integrated linkage map. The most favorable combination of alleles for these QTL was a+c.

Three QTL were identified with only one isolate. A QTL was detected on LG12 with isolate 1066. Its effect was very strong $\left(R^{2}=82.7 \%\right)$. Its likelihood peak was at the same map position as the major gene identified with the necrosis symptom scored on leaves, and favorable effects were derived from the same allele of 'Discovery' (a). No other QTL was detected with isolate 1066 (race 7), neither on the entire progeny nor in the part of the

TABLE 3. Mean infection type and mean sporulation of the apple genotypes 'Discovery' and 'TN10-8' according to the isolate tested ${ }^{\mathrm{a}}$

\begin{tabular}{lcclcc}
\hline & \multicolumn{2}{c}{ Infection type } & & \multicolumn{2}{c}{ Sporulation } \\
\cline { 2 - 3 } \cline { 5 - 6 } Inoculum & Discovery & TN10-8 & & Discovery & TN10-8 \\
\hline 1066 & $1.7_{\mathrm{B}}$ & $4.3_{\mathrm{AB}}$ & & $0.0_{\mathrm{B}}$ & $3.0_{\mathrm{B}}$ \\
EU-D42 & 5.0 & 5.0 & & 3.0 & 5.0 \\
104 & $0.7_{\mathrm{B}}$ & $1.7_{\mathrm{C}}$ & & $0.0_{\mathrm{B}}$ & $0.0_{\mathrm{C}}$ \\
Gd-CH & 0.0 & 2.0 & & 0.0 & 0.0 \\
EU-NL24 & $4.0_{\mathrm{A}}$ & $5.0_{\mathrm{A}}$ & & $2.0_{\mathrm{A}}$ & $6.8_{\mathrm{A}}$ \\
EU-B04 & $2.0_{\mathrm{B}}$ & $3.0_{\mathrm{BC}}$ & & $0.0_{\mathrm{B}}$ & $1.0_{\mathrm{BC}}$ \\
MLI & $1.0_{\mathrm{B}}$ & $2.2_{\mathrm{C}}$ & & $0.0_{\mathrm{B}}$ & $0.2_{\mathrm{C}}$ \\
\hline
\end{tabular}

a Replicates of 'Discovery' and 'TN10-8' were included in the randomized complete block design used for the pathological tests of the progeny. Only one replicate was available for both isolate EU-D42 and isolate Gd-CH so results obtained with these isolates could not be included in this test. For each parameter used (within columns), means obtained with different isolates were compared using a Bonferroni test (type I experimentwise error $=5 \%$ ). The letters $\mathrm{A}, \mathrm{B}$, and $\mathrm{C}$ following means refer to the different groups that could be distinguished between means by this test. 
progeny without necrosis on leaves. Two other isolate-specific QTL were detected with isolate EU-B04 on LG13 and with isolate EU-NL24 on LG15. Their effects were weak $\left(R^{2}<8 \%\right)$.

\section{DISCUSSION}

Experimental design. Scab incidence varied greatly between experiments in the progeny, which displayed on average a strong to intermediate resistance after inoculation with isolates 104, EUB04, Gd-CH, MLI, and 1066, whereas it was susceptible to isolates EU-D42, 302, and EU-NL24 (Table 2). These differences probably reflect differences in aggressiveness or in virulence between isolates, since inoculations and environmental conditions were rather homogeneous between experiments.
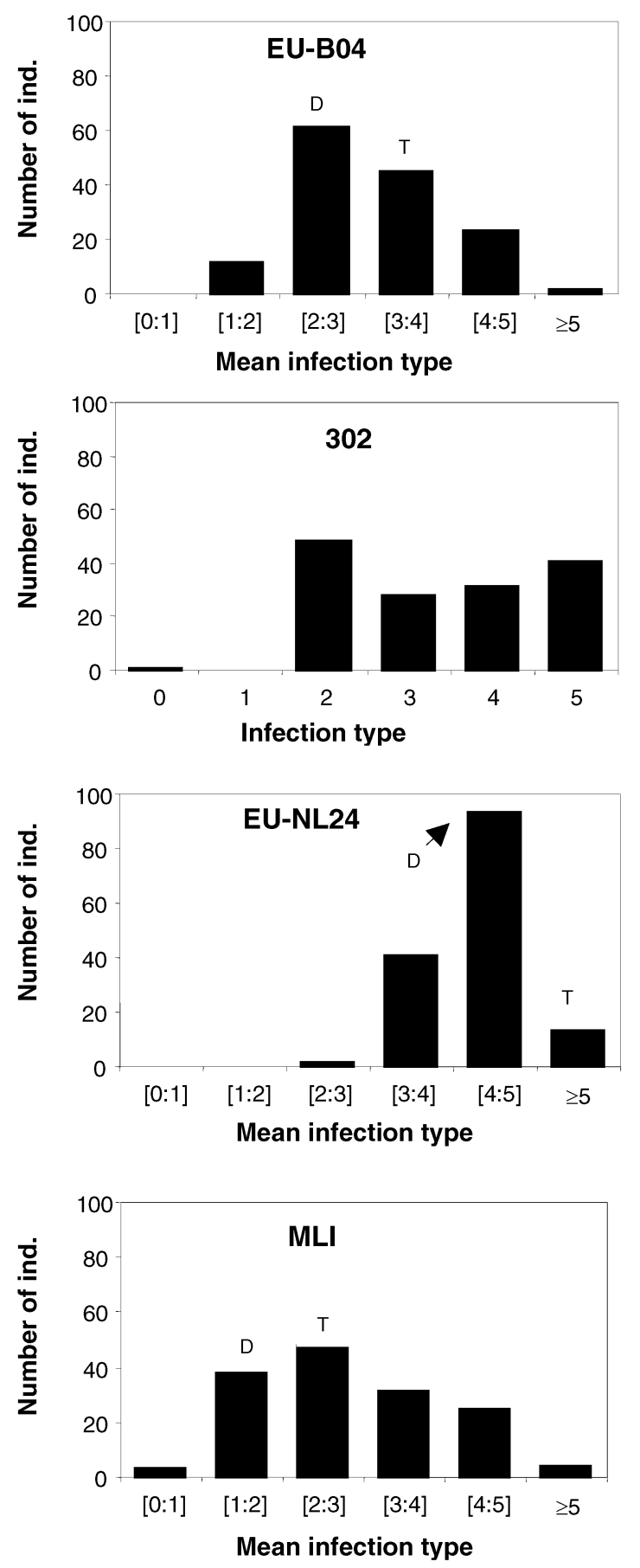

Resistance of the progeny to isolate 104 was particularly strong. Some of the individuals scored as resistant might be escapes. Some nongrowing individuals also could have been accidentally scored, leading to nonrepresentative scores, owing to the occurrence of ontogenic resistance in the older leaves. Nevertheless, the calculation of the mean infection type over replicates reduced the error due to the putative occurrence of escapes. A higher concentration for isolate $104\left(>3 \times 10^{5}\right.$ spores per ml) should be used in further experiments to confirm the high resistance level of the progeny. Similarly, a lower inoculum concentration $\left(<3 \times 10^{5}\right.$ spores per $\mathrm{ml}$ ) should be used in further experiments to confirm the high susceptibility of the progeny to isolates EU-D42 and EU-NL24.

In spite of the lack of variability observed in the progeny for some of the isolates tested, several QTL could be detected with
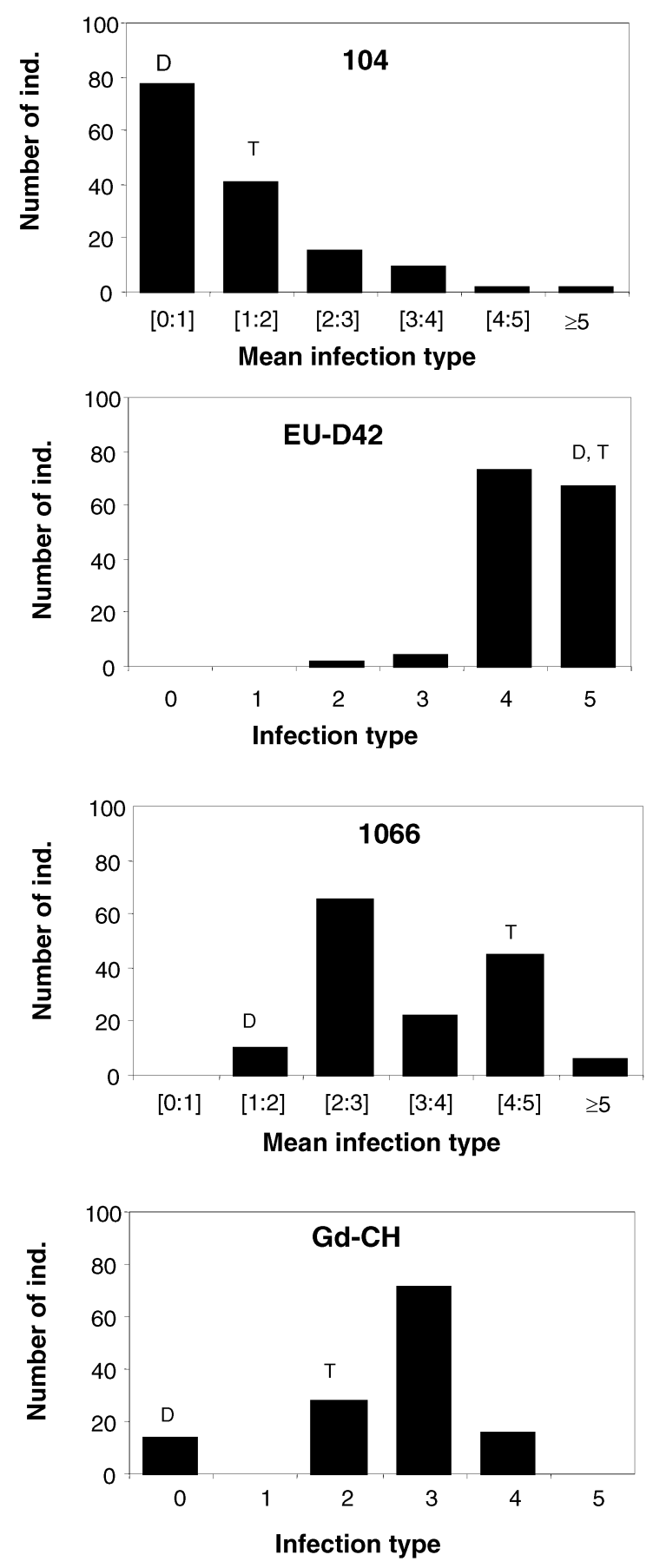

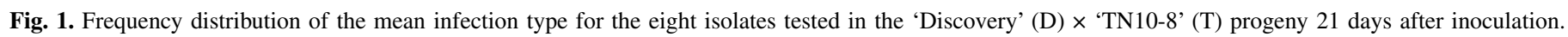

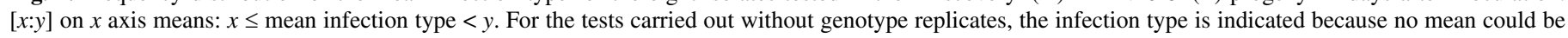
calculated. For isolate 302, parental genotypes were not available and could not be inoculated with the progeny. 
every isolate. One to five resistance loci were identified according to the isolate tested. For each isolate, the comparison between broad-sense heritability and total phenotypic variation accounted for by QTL (Table 2) shows that there is often an important part of phenotypic variation that remains unexplained. This may result from (i) the reduced size of our progeny, which could have prevented the detection of minor QTL; (ii) the existence of resistance loci in genomic regions not covered by our genetic map; or (iii)

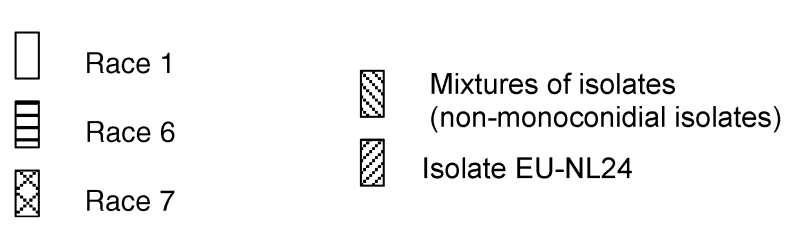

LG5

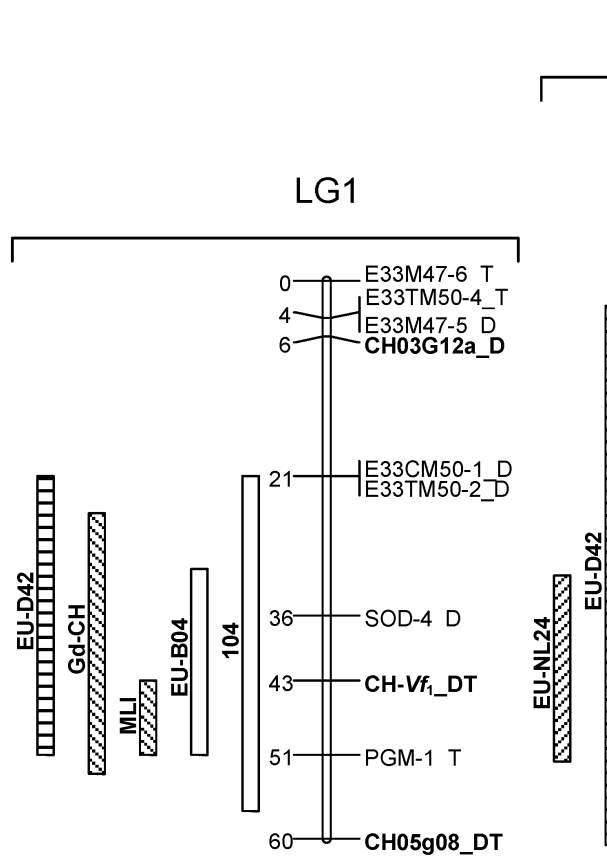

LG2
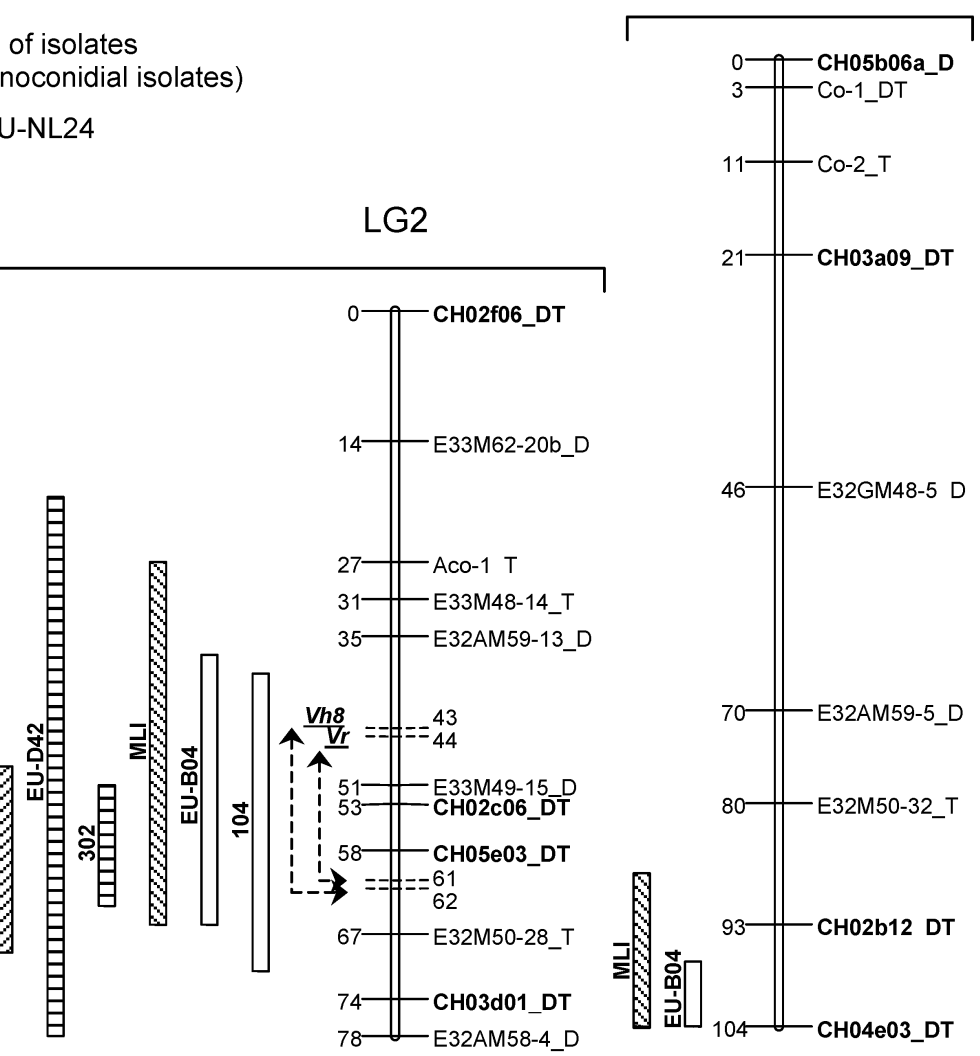

LG17
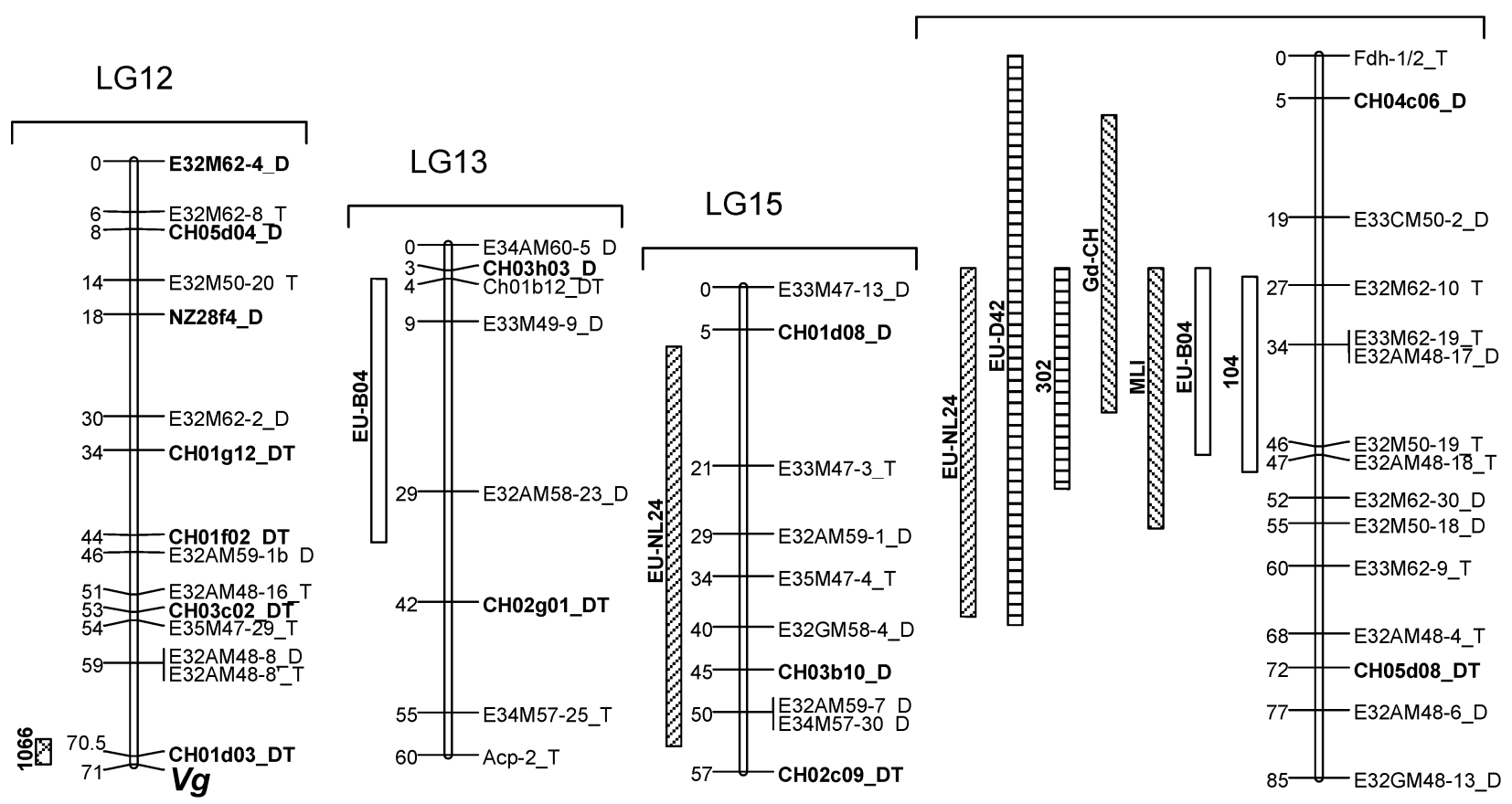

Fig. 2. Genetic positions (in centimorgans) of the scab resistance quantitative trait loci (QTL) detected by restricted multiple QTL mapping in the 'Discovery' (D) $\times$ 'TN10-8' (T) progeny with the mean infection type, 21 days after inoculation, with a LOD of $>3$. QTL are represented by rectangles. Only the linkage groups (LG) carrying resistance loci are represented. Their denotation follows the denotation of Maliepaard et al. (38). CH0.y, microsatellite markers, developed at ETH Zürich by Liebhard et al. (34); ExMy, amplified fragment length polymorphism markers; and other markers: enzymes. The letters D, T, or DT after every marker indicate the name of the parent(s) for which the marker was heterozygous. The two possible positions of the major scab resistance genes $V r$ and $V h 8$, mapped in other progenies $(7,25)$, are indicated on LG2. 
epistatic interactions between genes dispersed in the genome, which were not tested in this study. Several studies actually demonstrated that epistasis may occur between different loci involved in partial disease resistance $(1,30,39,50)$.

Numerous QTL were detected at similar positions on LG1, LG2, and LG17 after independent experiments with different isolates. This increases the confidence in the weak effect QTL detected at these positions with some of the isolates (for instance, EU-NL24 on LG1 and 104 on LG2). QTL with overlapping confidence intervals and close likelihood peaks might be considered as one single QTL. We thus consider that we detected only three different major QTL on LG1, LG2, and LG17 with broad-spectra of action toward the isolates tested, and a single QTL for resistance to two isolates on LG5. It does not imply that there is one single gene determining partial scab resistance in each of these genomic regions; confidence intervals are too wide to determine if there is one single gene or several linked genes underlying each QTL.

Three major genomic regions involved in partial resistance to scab in apple. Each of the three genomic regions detected on LG1, LG2, and LG17 in this study was identified with most of the isolates tested. The other QTL on LG5, LG12, LG13, and LG15 were detected with only one or two different isolates. These results might be compared with results previously obtained in other apple progenies. Five QTL for scab resistance were already reported by Durel et al. (17) in a 'Prima' $\times$ 'Fiesta' progeny inoculated in a controlled climatic chamber with isolates 302 and EUD42 (race 6). One of these QTL was identified on LG1 with isolate 302 in 'Prima' around $V f$, and a second QTL for resistance to both isolates EU-D42 and 302 was detected on LG17 in
'Fiesta'. Seven QTL were identified by Liebhard et al. (36) in a 'Fiesta' $x$ 'Discovery' progeny in field conditions. One of these QTL was mapped on LG17 in both 'Fiesta' and 'Discovery'. Our results thus confirm the involvement of these genomic regions on LG1 and LG17 in partial scab resistance.

We also detected new genomic regions associated with partial resistance to scab. In particular, the broad-spectrum QTL detected on LG2 with every isolate, except isolates 1066 and Gd-CH, was never identified previously. Similarly, the QTL detected on LG5 (with isolates MLI and EU-B04), LG13 (isolate EU-B04), and LG15 (isolate EU-NL24) in the 'Discovery' $x$ 'TN10-8' progeny were never identified previously. Conversely, several QTL identified in the previous studies were not confirmed here. Most of the QTL identified in the 'Fiesta' $\times$ 'Discovery' progeny were not identified in this study. A strong-effect QTL was detected at the same location on LG11 in both the 'Prima' $\times$ 'Fiesta' and the 'Fiesta' $\times$ 'Discovery' progenies but was not detected here, though it was reported by Liebhard et al. (36) that 'Discovery' carries a favorable allele at this QTL.

The observation of QTL detected in only one or two of these three progenies may be attributed to several reasons: (i) parents of the three progenies are different, except 'Discovery' which is common to two of the progenies; (ii) the isolates tested in these progenies are different, except isolates EU-D42 and 302 which were tested in the 'Prima' $\times$ 'Fiesta' and the 'Discovery' $\times$ 'TN108 ' progenies; (iii) greenhouse and field conditions are very different in terms of plants age and environmental conditions, so that different QTL might be expressed in these different environments; and (iv) for the common parent 'Discovery', QTL expression might be influenced differently by the genetic background of the

TABLE 4. Parameters associated with the quantitative trait loci (QTL) for scab resistance detected by restricted multiple QTL mapping with the mean infection type scored 21 days after inoculation in the 'Discovery' $\times$ 'TN10-8' progeny, according to the linkage group (LG) on which they were mapped and to the isolate tested

\begin{tabular}{|c|c|c|c|c|c|c|c|c|c|c|c|c|}
\hline LG & Isolate & $\mathrm{LOD}^{\mathrm{a}}$ & $\begin{array}{c}\text { Distance } \\
(\mathrm{cM})^{\mathrm{b}}\end{array}$ & $R^{2}(\%)^{\mathrm{c}}$ & $\begin{array}{c}\text { Confidence } \\
\text { interval }(\mathrm{cM})\end{array}$ & $\mathrm{ac}^{\mathrm{d}}$ & $\mathrm{ad}^{\mathrm{d}}$ & $b c^{d}$ & $\mathrm{bd}^{\mathrm{d}}$ & Map $^{e}$ & $\begin{array}{c}\text { Favorable } \\
\text { allele }^{\mathrm{f}}\end{array}$ & Markerg \\
\hline \multirow[t]{5}{*}{ LG1 } & EU-B04 & 15.86 & 45.4 & 25.6 & 19.2 & 1.86 & 2.75 & 2.11 & 2.94 & $\mathrm{~T}$ & $\mathrm{c}$ & $\mathrm{CH}-V f_{1}$ \\
\hline & 104 & 4.17 & 52.6 & 23.2 & 35.2 & 0.94 & 1.58 & 0.97 & 2.27 & $\mathrm{~T}$ & c & PGM-1 \\
\hline & EU-NL24 & 2.18 & 42.1 & 4.1 & 60.4 & 3.36 & 3.62 & 3.22 & 3.38 & $\mathrm{~T}$ & $\mathrm{c}$ & $\mathrm{CH}-V f_{1}$ \\
\hline & MLI & 26.59 & 47.4 & 51.1 & 7.2 & 1.49 & 3.14 & 1.89 & 3.46 & $\mathrm{~T}$ & $\mathrm{c}$ & PGM-1 \\
\hline & Gd-CH & 4.62 & 43.4 & 12.7 & 29.4 & 1.51 & 2.37 & 1.84 & 2.47 & $\mathrm{~T}$ & $\mathrm{c}$ & $\mathrm{CH}-V f_{1}$ \\
\hline \multirow[t]{4}{*}{ LG2 } & EU-B04 & 6.99 & 57.1 & 9.5 & 21.6 & 1.87 & 1.60 & 2.25 & 2.16 & $\mathrm{D}$ & $\mathrm{a}$ & $\mathrm{CH} 05 \mathrm{e} 03$ \\
\hline & EU-D42 & 4.06 & 44.7 & 13.0 & 49.9 & 4.17 & 3.58 & 4.08 & 3.98 & $\mathrm{D}+\mathrm{T}$ & $a+d$ & E33M49-15 \\
\hline & EU-NL24 & 12.60 & 58.3 & 25.7 & 20.7 & 3.37 & 3.47 & 4.14 & 4.08 & D & $\mathrm{a}$ & $\mathrm{CH} 05 \mathrm{e} 03$ \\
\hline & MLI & 3.88 & 44.7 & 5.1 & 42.7 & 1.51 & 1.04 & 1.76 & 1.20 & $\mathrm{~T}$ & d & $\mathrm{CH} 02 \mathrm{c} 06$ \\
\hline \multirow[t]{2}{*}{ LG5 } & EU-B04 & 12.57 & 102.6 & 20.8 & 5.3 & 1.66 & 1.97 & 2.78 & 2.39 & $\mathrm{D}$ & $\mathrm{a}$ & $\mathrm{CH} 04 \mathrm{e} 03$ \\
\hline & MLI & 5.40 & 100.6 & 12.5 & 15.8 & 1.34 & 2.11 & 2.53 & 2.06 & $\mathrm{D}+\mathrm{T}$ & $a+c$ & $\mathrm{CH} 04 \mathrm{e} 03$ \\
\hline LG12 & 1066 & 62.81 & 70.7 & 82.7 & 3.4 & 2.06 & 1.98 & 4.17 & 3.83 & $\mathrm{D}$ & $\mathrm{a}$ & $V g$ \\
\hline & 104 & 7.12 & 35.5 & 19.4 & 23.2 & 0.96 & 0.77 & 1.88 & 1.85 & $\mathrm{D}$ & $\mathrm{a}$ & E32AM48-17 \\
\hline & 302 & 5.64 & 39.5 & 13.1 & 26.2 & 1.90 & 1.98 & 2.80 & 2.90 & $\mathrm{D}$ & $\mathrm{a}$ & E32AM48-17 \\
\hline & EU-D42 & 3.16 & 41.5 & 9.0 & 67.7 & 4.05 & 4.40 & 4.25 & 4.60 & $\mathrm{D}+\mathrm{T}$ & $a+c$ & E32AM48-17 \\
\hline & EU-NL24 & 4.07 & 39.5 & 10.0 & 41.1 & 3.34 & 3.81 & 3.77 & 3.81 & $\mathrm{D}+\mathrm{T}$ & $a+c$ & E32AM48-17 \\
\hline & MLI & 5.00 & 37.5 & 4.7 & 30.2 & 1.51 & 1.99 & 2.18 & 2.35 & $\mathrm{D}$ & $\mathrm{a}$ & E32AM48-17 \\
\hline & $\mathrm{Gd}-\mathrm{CH}$ & 6.35 & 20.6 & 19.0 & 34.8 & 1.47 & 1.60 & 2.44 & 2.58 & $\mathrm{D}$ & a & E33CM50-2 \\
\hline
\end{tabular}

${ }^{a}$ Maximum LOD (logarithm of odds ratio) score (likelihood peak).

${ }^{\mathrm{b}}$ Map position of the maximum LOD score.

${ }^{c}$ Proportion of phenotypic variation explained by individual QTL.

' Mean infection type associated with the four genotypic classes (ac, ad, bc, or bd) present in 'Discovery' (ab) and 'TN10-8' (cd) at the likelihood peak of each QTL.

e Parental map on which each QTL was detected: D, map of 'Discovery'; T, map of 'TN10-8'; and D+T, integrated linkage map.

${ }^{\mathrm{f}}$ Most favorable parental allele associated with scab resistance; when QTL were detected only on the integrated linkage map, a combination of alleles is indicated $(\mathrm{a}+\mathrm{c}$ or $\mathrm{a}+\mathrm{d})$.

g Molecular marker the closest to the likelihood peak of each QTL (integrated linkage map). 
other parent, either 'TN10-8' or 'Fiesta'. To allow relevant comparisons, the 'Prima' $\times$ 'Fiesta' and 'Fiesta' $\times$ 'Discovery' progenies should be tested with the same isolates that were used here, in similar greenhouse conditions.

Co-localizations of QTL with major genes. Three major scab resistance genes previously mapped in other apple progenies colocalize with the QTL identified on LG1 and LG2 in the present study. On LG1, most of the likelihood peaks of the QTL detected with the different isolates tested were located a maximum of $4 \mathrm{cM}$ from the microsatellite marker $\mathrm{CH}-V f_{1}$ (except for isolate 104 with $9 \mathrm{cM}$ ). This marker is very tightly linked to the $V f$ locus in other apple genotypes (A. Patocchi, personal communication). On LG2, the major scab resistance gene $V r$ was recently mapped at $7.8 \mathrm{cM}$ from the microsatellite marker $\mathrm{CH} 02 \mathrm{~b} 10$ (27). This marker was mapped $1 \mathrm{cM}$ above the microsatellite marker CH02c06 in the 'Fiesta' $\times$ 'Discovery' progeny (34), which is close to most of the likelihood peaks of the QTL detected on LG2 (maximum $8 \mathrm{cM}$ ). In addition, the position of the scab R-gene Vh 8 can be estimated a maximum of $9.5 \mathrm{cM}$ from $\mathrm{CH} 02 \mathrm{~b} 10$ (8). There are two possible positions for each gene on the 'Discovery' $\times$ 'TN10-8' map (Fig. 2).

Co-localizations between major resistance genes and resistance QTL mapped in distinct progenies of the same species were frequently observed in a number of other pathosystems $(3,9,20-22$, $28,31,54)$. Most of the molecularly characterized R-genes belong either to families of tightly linked genes or to allelic series (27). Therefore, QTL and major genes co-localizing could be either members of the same allelic series, as suggested by Robertson (49), or closely linked members of the same gene family segregating in two distinct progenies. At the molecular level, it is clear that some QTL share structural and functional similarities with Rgenes. It has been demonstrated that genes sharing a common structure with R-genes could trigger a weak resistance. For instance, in rice, the gene $X a 21 D$, belonging to the $X a 21$ gene family, was shown to confer a partial resistance phenotype to bacterial blight (55). A similar case was observed in tomato with a member of the multigene family $I 2 C$, referred to as $I 2 C-I$ (41).

The co-localization of the QTL detected on LG1 with $V f$ raises the possibility that both types of genes belong to the same gene family or to the same allelic series. It was recently reported that $V f$ probably belongs to a family of closely linked genes $(52,57)$, called $H c r V f$, with strong homologies with the $C f$ resistance gene family members, particularly to $C f 9$ (52). The gene (or genes) underlying the QTL detected in the 'Discovery' $\times$ 'TN10-8' progeny might be allelic or paralogous members of this gene family and thus share strong structural and functional similarities with these genes. Similarly, the gene (or genes) underlying the QTL detected on LG2 might be related to $V r$ or to $V h 8$, which have not yet been characterized. Conversely, no QTL was detected close to the major gene $V g$ on LG12 with other isolates, except isolate 1066. The same situation was observed in the 'Prima' $\times$ 'Fiesta' progeny, where $V g$ was already mapped (18). This does not mean that $V g$ is the only functional scab resistance allele in this genomic region. It could belong to a gene family or to an allelic series of which other members have not yet been identified.

Isolate specificity of the QTL. The use of eight isolates of $V$. inaequalis in this experiment allowed us to determine the individual spectra of action of the detected QTL. Two isolate-specific QTL were found on LG13 and LG15 with isolates EU-B04 and EU-NL24, respectively. A more complex situation was found for the other QTL identified, which were neither clearly isolate-specific nor completely generalists. The same QTL was detected on LG2 with every isolate except isolates $\mathrm{Gd}-\mathrm{CH}$ and 1066, but favorable effects derived from three different alleles according to the isolate $(\mathrm{a}, \mathrm{c}$, or $\mathrm{d})$ or from a combination between two alleles. Therefore, there were at least three different resistance alleles with different specificities on this LG. In contrast, all favorable effects on LG1, LG5, and LG17 were conferred by the same allele (c, a, and a, respectively), with an exception on LG17 where the most favorable effects sometimes derived from the combination of alleles a+c. In these cases, favorable effects may derive either from one single gene with a broad spectrum of action or from several more specific closely linked genes in coupling phase.

Most studies in which several isolates were used to detect QTL for resistance report either only broad-spectrum QTL and no isolate-specific QTL $(40,58)$ or a combination of broad-spectrum QTL with strong effects on resistance and isolate-specific QTL with minor effects on resistance $(2,9,10,47)$. Our results are more complex, since (i) some of the isolate-specific QTL detected had strong effects on resistance (for instance the QTL on LG5), (ii) some QTL had a broad spectrum of action but it was never complete (QTL on LG1, LG2, and LG17), and (iii) the QTL on LG2 displayed alleles conferring different specificities. This greater complexity probably partly derives from the larger number of isolates tested in this study. If more isolates belonging to distinct pathotypes were tested in other pathosystems, more QTL with incomplete spectrum of action, or with alleles conferring different specificities, might be found.

The identification of isolate- or race-specific QTL in a number of pathosystems $(9,10,16,21,31,47)$ and the co-localization of QTL with R-genes suggest that some QTL are involved in pathogen recognition. Parlevliet and Zadoks (45) proposed that genes for partial resistance to pathogens might be, as well as major resistance genes, involved in a gene-for-gene relationship with avirulence genes of the pathogen, either major or minor. Nevertheless, to our knowledge, the evidence of a direct interaction between the product of a QTL for resistance and the matching avirulence factor is still lacking. Interestingly, in our study, the QTL on LG1 had strong effects on the isolates blocked by $V f$ but weak or no effects on the isolates able to overcome $V f$. From these results, it can be hypothesized that the gene (or genes) underlying this QTL is involved in a gene-for-gene relationship with avrVf, or with another avirulence gene present only in the races blocked by $V f$.

Conversely, the QTL on LG17 was involved in the resistance to every isolate except isolate 1066 . It does not co-localize with any known major resistance gene, and one single favorable allele at this QTL conferred resistance. Therefore, this region might be involved in general, nonspecific defense mechanisms. The absence of QTL for resistance to isolate 1066 might be due to the strong effect of $V g$, preventing the detection of QTL with smaller effects.

Identification and denotation of a major resistance gene. The necrosis symptom scored on leaves was clearly associated with resistance, though a few genotypes displayed both sporulation and necrosis symptom. In fact, a strong QTL $\left(R^{2}=82.7 \%\right)$ was detected at the same location as the major resistance gene causing the necrosis symptom. This major resistance gene is probably $V g$ because (i) the necrosis symptom it causes is very similar to the symptom caused by $V g$ in 'Golden Delicious' and 'Prima' $(4,18)$ and (ii) its map position at the bottom of LG12 is the same as the position of $V g$ (18). The pedigrees of 'Prima' and 'Discovery' are not known beyond the grandparents, but it can be hypothesized that 'Prima', 'Golden Delicious', and 'Discovery' share a common ancestor carrying $V g$.

Consequences for the construction of scab-resistant cultivars in apple. The QTL on LG17 is particularly interesting for breeding purposes because it was detected with every isolate except isolate 1066 (race 7) in the greenhouse, it was detected in field conditions (36), and it is present in two distinct cultivars (Fiesta and Discovery). The QTL on LG2 is also of high interest because it confers a high resistance level against some strains of the new races 6 and 7. Nevertheless, the different favorable alleles with complementary specificities at this QTL might be difficult to introduce in the same genotype since some of them are in repulsion phase. The QTL on LG2 and LG17 are flanked by several 
microsatellite markers that can directly be used in marker-assisted selection. The major gene $V g$, though already overcome by races 1 to 6 , will be useful to confer resistance against race 7 once userfriendly molecular markers are available for marker-assisted selection. In the future, individuals carrying different combinations of QTL will be selected in this progeny and planted in an orchard where new races of $V$. inaequalis are present, in order to challenge the efficiency and the durability of their resistance to scab.

\section{ACKNOWLEDGMENTS}

This work was partly supported by the European project FAIR5 CT973898 (DARE: Durable Apple Resistance in Europe). We thank F. Laurens and B. Le Cam for useful comments on the manuscript and A. Fouillet, V. Fouillet, J. Gaudin, M.-P. Joly, E. Ruiz, H. Labit, N. Vallet, and M. Stankiewicz for excellent technical assistance.

\section{LITERATURE CITED}

1. Ahmadi, N., Albar, L., Pressoir, G., Pinel, A., Fargette, D., and Ghesquiere, A. 2001. Genetic basis and mapping of the resistance to Rice yellow mottle virus. III. Analysis of QTL efficiency in introgressed progenies confirmed the hypothesis of complementary epistasis between two resistance QTL. Theor. Appl. Genet. 103:1084-1092.

2. Arru, L., Francia, E., and Pecchioni, N. 2003. Isolate-specific QTLs of resistance to leaf stripe (Pyrenophora graminea) in the 'Streptoe' $\times$ 'Morex' spring barley cross. Theor. Appl. Genet. 106:668-675.

3. Bai, Y., Huang, C.-C., van der Hulst, R., Meijer-Dekens, F., Bonnema, G., and Lindhout, P. 2003. QTLs for tomato powdery mildew resistance (Oidium lycopersici) in Lycopersicon parviflorum G1.1601 co-localize with two qualitative powdery mildew resistance genes. Mol. PlantMicrobe Interact. 16:169-176.

4. Bénaouf, G., and Parisi, L. 1997. Pathogenicity of Venturia inaequalis strains from Malus floribunda 821: Comparison with race 6 on apple clones. Pages 8-11 in: Integrated Control of Pome Fruit Diseases. A. M. Berrie, X. M. Xu, D. C. Harris, A. L. Roberts, K. Evans, D. J. Barbara, and C. Gessler, eds. IOBC/WPRS Bull. 20.

5. Bénaouf, G., and Parisi, L. 2000. Genetics of host-pathogen relationships between Venturia inaequalis races 6 and 7 and Malus species. Phytopathology 90:236-242.

6. Bénaouf, G., Parisi, L., and Laurens, F. 1997. Inheritance of Malus floribunda clone 821 resistance to Venturia inaequalis. Pages 1-7 in: Integrated Control of Pome Fruit Diseases. A. M. Berrie, X. M. Xu, D. C. Harris, A. L. Roberts, K. Evans, D. J. Barbara, and C. Gessler, eds. IOBC/WPRS Bull. 20.

7. Bus, V., Gardiner, S., Basset, H., Ranatunga, C., and Rikkerink, E. 1999. Marker assisted selection for pest and disease resistance in the New Zealand apple breeding programme. Acta Hortic. 538:541-547.

8. Bus, V., Laurens, F., Gardiner, S., Plummer, K., and Rikkerink, E. 2003. Molecular detection reveals a new gene-for-gene combination in the Malus-apple scab interaction. Page 217 in: Proc. 8th Int. Congr. Plant Pathol., Vol. 2. Christchurch, New Zealand.

9. Caranta, C., Lefebvre, V., and Palloix, A. 1997. Polygenic resistance of pepper to potyviruses consists of a combination of isolate-specific and broad-spectrum quantitative trait loci. Mol. Plant-Microbe Interact. 10:872-878.

10. Chen, H., Wang, S., Xing, Y., Xu, C., Hayes, P. M., and Zhang, Q. 2003. Comparative analyses of genomic locations and race specificities of loci for quantitative resistance to Pyricularia grisea in rice and barley. Proc. Natl. Acad. Sci. 100:2544-2549.

11. Chevalier, M., Lespinasse, Y., and Renaudin, S. 1991. A microscopic study of the different classes of symptoms coded by the $V f$ gene in apple for resistance to scab (Venturia inaequalis). Plant Pathol. 40:249-256.

12. Chevreau, E., Manganaris, A. G., and Gallet, M. 1999. Isozyme segregation in five apple progenies and potential use for map construction. Theor. Appl. Genet. 98:329-336.

13. Conner, P. J., Brown, S. K. and Weeden, N. F. 1997. Randomly amplified polymorphic DNA-based genetic linkage maps of three apple cultivars. J. Am. Soc. Hortic. Sci. 197:350-359.

14. Crosby, J. A., Janick, J., Pecknold, P. C., Korban, S. S., O'Connor, P. A., Ries, S. M., Goffreda, J., and Voordeckers, A. 1992. Breeding apples for scab resistance-1945-1990. Fruit Var. J. 46:145-166.

15. Croxall, H. E., Gwynne, D. C., and Jenkins, J. E. E. 1952. The rapid assessment of apple scab on leaves. Plant Pathol. 1:39-41.

16. Dogimont, C., Leconte, L., Perin, C., Thabuis, A., Lecoq, H., and Pitrat, M. 2000. Identification of QTL contributing to resistance to different strains of cucumber mosaic cucumovirus in melon. Acta Hortic. 510:391-398.
17. Durel, C.-E., Parisi, L., Laurens, F., van de Weg, E., Liebhard, R., Koller, B., and Jourjon, M. F. 2003. Genetic dissection of partial resistance against two monoconidial strains of the new race 6 of Venturia inaequalis in apple. Genome 46:224-234.

18. Durel, C.-E., van de Weg, E., Venisse, J. S., and Parisi, L. 2000. Localisation of a major gene for apple scab resistance on the European genetic map of the Prima $\times$ Fiesta cross. Pages 245-246 in: Integrated Control of Pome Fruit Diseases. L. Parisi, ed. IOBC/WPRS Bull. 23.

19. Flor, H. H. 1971. Current status of the gene-for-gene concept. Annu. Rev. Phytopathol. 9:75-96.

20. Gebhardt, C., and Valkonen, J. P. T. 2001. Organization of genes controlling disease resistance in the potato genome. Annu. Rev. Phytopathol. 39:79-102.

21. Geffroy, V., Sevignac, M., De Oliveira, J. C., Fouilloux, G., Skroch, P., Thoquet, P., Gepts, P., Langin, T., and Dron, M. 2000. Inheritance of partial resistance against Colletotrichum lindemuthianum in Phaseolus vulgaris and co-localization of quantitative trait loci with genes involved in specific resistance. Mol. Plant-Microbe Interact. 13:287-296.

22. Ghesquières, A., Albar, L., Lorieux, M., Ahmadi, N., Fargette, D., Huang, N., McCouch, S., and Notteghem, J. 1997. A major quantitative trait locus for Rice yellow mottle virus resistance maps to a cluster of blast resistance genes on chromosome 12. Phytopathology 87:1243-1249.

23. Gianfranceschi, L., Seglias, N., Tarchini, R., Komjanc, M., and Gessler, C. 1998. Simple sequence repeats for the genetic analysis of apple. Theor. Appl. Genet. 96:1069-1076.

24. Grattapaglia, D., and Sederoff, R. 1994. Genetic linkage maps of Eucalyptus grandis and E. urophylla using a pseudo-testcross mapping strategy and RAPD markers. Genetics 137:1121-1137.

25. Hemmat, M., and Brown, S. K. 2002. Tagging and mapping scab resistance genes from R12740-7A apple. J. Am. Soc. Hortic. Sci. 127:365-370.

26. Hemmat, M., Weeden, N. F., Manganaris, A. G., and Lawson, D. M. 1994. Molecular linkage map for apple. J. Hered. 85:4-11.

27. Hulbert, S. H., Webb, C. A., Smith, S. M., and Sun, Q. 2001. Resistance gene complexes: Evolution and utilization. Annu. Rev. Phytopathol. 39:285-312.

28. Keller, M., Keller, B., Schachermayr, G., Winzeler, M., Schmid, J. E., Stamp, P., and Messmer, M. M. 1999. Quantitative trait loci for resistance against powdery mildew in a segregating wheat $\times$ spelt population. Theor. Appl. Genet. 98:903-912.

29. Laurens, F. 1999. Review of the current apple breeding programs in the world: Objectives for scion cultivar improvement. Acta Hortic. 484:163170 .

30. Lefebvre, V., and Palloix, A. 1996. Both epistatic and additive effects of QTL are involved in polygenic induced resistance to disease: A case study, the interaction pepper-Phytophthora capsici Leonian. Theor. Appl. Genet. 93:503-511.

31. Leonards-Schippers, C., Gieffers, W., Schafer-Pregl, R., Ritter, E., Knapp, S. J., Salamini, F., and Gebhardt, C. 1994. Quantitative resistance to Phytophthora infestans in potato: A case study for QTL mapping in an allogamous plant species. Genetics 137:67-77.

32. Lespinasse, Y. 1989. Breeding pome fruits with stable resistance to diseases. Genes, resistance mechanisms, present work and prospects. Pages 100-115 in: Integrated Control of Pome Fruit Diseases. C. Gessler, D. J. Butt, and B. Koller, eds. IOBC/WPRS Bull. 2.

33. Lespinasse, Y., Durel, C.-E., Parisi, L., Laurens, F., Chevalier, M., and Pinet, C. 2000. A European project: D.A.R.E.-Durable apple resistance in Europe. Acta Hortic. 538:197-200.

34. Liebhard, R., Gianfranceschi, L., Koller, B., Ryder, C. D., Tarchini, R., van de Weg, E., and Gessler, C. 2002. Development and characterisation of 140 new microsatellites in apple (Malus $\times$ domestica Borkh.). Mol. Breed. 10:217-241.

35. Liebhard, R., Koller, B., Gianfranceschi, L., and Gessler, C. 2003. Creating a saturated reference map for the apple (Malus pumila Mill.) genome. Theor. Appl. Genet. 106:1497-1508.

36. Liebhard, R., Koller, B., Patocchi, A., Kellerhals, M., Pfammatter, W., Jermini, M., and Gessler, C. 2003. Mapping quantitative field resistance against apple scab in a 'Fiesta' $\times$ 'Discovery' progeny. Phytopathology 93:493-501.

37. MacHardy, W. E. 1996. Apple Scab. Biology, Epidemiology, and Management. The American Phytopathological Society, St. Paul, MN.

38. Maliepaard, C., Alston, F., van Arkel, G., Brown, L., Chevreau, E., Dunemann, F., Evans, K. M., Gardiner, S., Guilford, P., van Heusden, A. W., Janse, J., Laurens, F., Lynn, J. R., Manganaris, A. G., den Nijs, A. P. M., Periam, N., Rikkerink, E., Roche, P., Ryder, C., Sansavini, S., Schmidt, H., Tartarini, S., Verhaegh, J. J., Vrielink-van Ginkel, M., and King, G. J. 1998. Aligning male and female linkage maps of apple (Malus pumila Mill.) using multi-allelic markers. Theor. Appl. Genet. 97:60-73.

39. Manzanares-Dauleux, M. J., Delourme, R., Baron, F., and Thomas, G. 2000. Mapping of one major gene and of QTL involved in resistance to clubroot in Brassica napus. Theor. Appl. Genet. 101:885-891. 
40. Niks, R. E., Fernandez, E., van Happeren, B., Bekele Aleye, B., and Martinez, F. 2000. Specificity of QTLs for partial and non-host resistance of barley to leaf rust fungi. Acta Phytopathol. Entomol. Hun. 35:13-21.

41. Ori, N., Eshed, Y., Paran, I., Presting, G., Aviv, D., Tanksley, S., Zamir, D., and Fluhr, R. 1997. The $I 2 C$ family from the wilt disease resistance locus $I 2$ belongs to the nucleotide binding, leucine-reach repeat superfamily of plant resistance genes. Plant Cell 9:521-532.

42. Parisi, L., and Lespinasse, Y. 1996. Pathogenicity of Venturia inaequalis strains of race 6 on apple clones (Malus sp.). Plant Dis. 80:1179-1183.

43. Parisi, L., Lespinasse, Y., Guillaumes, J., and Kruger, J. 1993. A new race of Venturia inaequalis virulent to apples with resistance due to the Vf gene. Phytopathology 83:533-537.

44. Parlevliet, J. E. 2002. Durability of resistance against fungal, bacterial and viral pathogens: Present situation. Euphytica 124:147-156.

45. Parlevliet, J. E., and Zadoks, J. C. 1977. The integrated concept of disease resistance: A new view including horizontal and vertical resistance in plants. Euphytica 26:5-21.

46. Patocchi, A., Bigler, B., Koller, B., Liebhard, R., Kellerhals, M., and Gessler, C. 2003. Mapping of $V r 2$, a third apple scab resistance gene of Russian seedling (R12740-7A). Poster 540. Plant and Animal Genome XI Conference. Published online by Sherago International, New York.

47. Qi, X. 1999. Isolate-specific QTL for partial resistance to Puccinia hordei in barley. Theor. Appl. Genet. 99:877-884.

48. Roberts, A. L., and Crute, I. R. 1994. Apple scab resistance from Malus floribunda $821(V f)$ is rendered ineffective by isolates of Venturia inaequalis from Malus floribunda. Norw. J. Agric. Sci.17:403-406.

49. Robertson, D. 1985. A possible technique for isolating genic DNA for quantitative traits in plants. J. Theor. Biol. 117:1-10.
50. Saghai Maroof, M. A., Yue, Y. G., Xiang, Z. X., Stromberg, E. L., and Rufener, G. K. 1996. Identification of quantitative trait loci controlling resistance to grey leaf spot disease in maize. Theor. Appl. Genet. 93:539-546.

51. Van Ooijen, J. W. 1992. Accuracy of mapping quantitative trait loci in autogamous species. Theor. Appl. Genet. 84:803-811.

52. Vinatzer, B. A., Patocchi, A., Gianfranceschi, L., Tartarini, S., Zhang, H.B., Gessler, C., and Sansavini, S. 2001. Apple contains receptor-like genes homologous to the Cladosporium fulvum resistance gene family of tomato with a cluster of genes cosegregating with $V f$ apple scab resistance. Mol. Plant-Microbe Interact. 14:508-515.

53. Vos, P., Hogers, R., Bleeker, M., Reijans, M., Van de Lee, T., Hornes, M., Frijters, A., Pot, J., Peleman, J., Kuiper, M., and Zabeau, M. 1995. AFLP: A new technique for DNA fingerprinting. Nucleic Acids Res. 23:4407-4414.

54. Wang, G. L., Mackill, D. J., Bonman, J. M., McCouch, S. R., Champoux, M. C., and Nelson, R. J. 1994. RFLP mapping of genes conferring complete and partial resistance to blast in a durably resistant rice cultivar. Genetics 136:1421-1434.

55. Wang, G. L., Ruan, D. L., Song, W. Y., Sideris, S., Chen, L. L., Pi, L. Y., Zhang, S., Zhang, Z., Fauquet, C., Gaut, B., and Ronald, P. 1998. Xa21D encodes a receptor-like molecule with a leucine-rich repeat domain that determines race-specific recognition and is subject to adaptative evolution. Plant Cell 10:765-779.

56. Williams, E. B., and Kuc, J. 1969. Resistance in Malus to Venturia inaequalis. Annu. Rev. Phytopathol. 7:223-246.

57. Xu, M., and Korban, S. S. 2002 A cluster of four receptor-like genes in the $V f$ locus that confers resistance to apple scab disease. Genetics 162:1995-2006

58. Zhu, S., Leonard, K. J., and Kaeppler, H. F. 2003. Quantitative trait loci associated with seedling resistance to isolates of Puccinia coronata in oat. Phytopathology 93:860-866. 